\section{Line 63-1: A New Virus-resistant Transgenic Papaya}

\author{
Paula Tennant, ${ }^{1}$ Manoel T. Souza, Jr., ${ }^{2}$ and Dennis Gonsalves ${ }^{3}$ \\ Department Plant Pathology, Cornell University, Geneva, NY 14456
}

Maureen M. Fitch

U.S. Department of Agriculture, Agricultural Research Service, Hawaii Agricultural Research Center, 99-193 Aiea Heights Drive, HI 96701

Richard M. Manshardt

University of Hawaii, Department of Tropical Plant and Soil Sciences, 3190 Maile Way, Honolulu, HI 96822

\author{
Jerry L. Slightom \\ AureoGen Biosciences Suite 1200, SMIC, 4717 Campus Drive, Kalamazoo, \\ MI 49008
}

Additional index words pathogen-derived resistance, transgenic resistance

\begin{abstract}
The disease resistance of a transgenic line expressing the coat protein (CP) gene of the mild strain of the papaya ringspot virus (PRSV) from Hawaii was further analyzed against PRSV isolates from Hawaii and other geographical regions. Line 63-1 originated from the same transformation experiment that resulted in line 55-1 from which the transgenic commercial cultivars, 'Rainbow' and 'SunUp', were derived. Plants of line 63-1 used in this study consisted of a population from a self pollinated $R_{0}$ bisexual plant. ELISA and PCR tests provided evidence that there are at least two segregating $\mathrm{CP}$ loci. To allow for comparison with reactions of the previously reported line 55-1, virus isolates from Hawaii, Brazil, Thailand, and Jamaica were used to challenge seedlings of 63-1. Unlike line 55-1, a significant percentage of inoculated transgenic plants were susceptible to isolates from Hawaii. However, a proportion of plants were resistant to the non-Hawaiian isolates. In contrast, previous work showed that all plants of the hemizygous line 55-1 were susceptible to PRSV isolates from Brazil, Thailand, and Jamaica. Line 63-1, therefore, presents Hawaii with PRSV-resistant transgenic germplasm that could be used as a source of transgenes for resistance to PRSV isolates within and outside of Hawaii.
\end{abstract}

In 1998, two papaya ringspot virus (PRSV) resistant papaya cultivars, 'SunUp' and 'Rainbow', were released to growers in Hawaii(Fitch et al., 1992; Manshardt, 1998). The transgenic papayas have controlled the virus in Hawaii and according to recent figures out of the USDA's statistical service, 'Rainbow' presently makes up $47 \%$ of the Big Island's 779 papaya hectares. 'Rainbow' is a yellow-flesh $F_{1}$ hybrid of a cross between the transgenic cultivar 'SunUp' and nontransgenic cultivar 'Kapoho' (Manshardt,

Received for publication 6 Dec. 2004. Accepted for publication $15 \mathrm{Jan}$. 2005. The work represents a portion of the dissertation submitted in partial fulfillment for a $\mathrm{PhD}$ degree in Plant Pathology for the first author. We thank Sheri Ecker-Day and Martin Goffinet for assistance in the greenhouse and with grafting experiments, and Deon Mitchell and Vilma Gregory for the graphic arrangement. The first author was the recipient of a pre-doctoral fellowship from the Jamaica Agricultural Development Foundation (JADF).

${ }^{1}$ To whom reprints should be addressed; e-mail paula. tennant@uwimona.edu.jm.Current mailing address: Department of Life Sciences, University of the West Indies, Mona, Kingston 7, Jamaica.

${ }^{2}$ Current mailing address: Embrapa Genetic Resources \& Biotechnology, Brasília, DF, CP 02372, Brazil. CEP 70.770-900.

${ }^{3}$ Current address: Pacific Basin Agricultural Research Center, ARS-USDA, 99 Aupuni St., Ste. 204, Hilo, Hawaii 96720.
1998), which is the preferred nontransgenic cultivar in Hawaii. 'SunUp' is homozygous for the single coat protein $(\mathrm{CP})$ gene insert of the mild strain PRSV HA 5-1 (Manshardt, 1998) and was derived from the red-flesh transgenic papaya line 55-1 (Fitch et al., 1992).

Now over 5 years in the field, 'Rainbow' has offered durable resistance to PRSV in regions of Hawaii previously decimated by the disease (Ferreira et al., 2002). Papaya is the second most important fruit crop in Hawaii. Production virtually came to a halt in the 1950 s due to the spread of PRSV in the major growing region, Oahu island. This resulted in a relocation of the industry in the early 1960 s to the Puna District on Hawaii Island. However in 1992, PRSV was discovered in Puna which by then grew 95\% of Hawaii's papaya and by 1994, PRSV was widespread in Puna, causing extensive damage (Gonsalves, 1998). PRSV is a ssRNA potyvirus (Purcifull et al., 1984) transmitted by aphids. Severe infection debilitates the trees while fruits develop ringspot blemishes (Purcifull et al., 1984). The virus affects all major papaya production areas, including Brazil, the Caribbean, Mexico, Philippines, Taiwan, Thailand, and China.

Initial greenhouse studies of transgenic line 55-1, hemizygous for the CP gene, showed that although the plants were resistant to Hawaiian isolates, they were susceptible to PRSV isolates from 11 geographical regions, including Bahamas, Florida, Mexico, Jamaica, Brazil, and Thailand (Tennant et al., 1994). Later work (Tennant et al., 2001) showed that resistance of line 55-1 is RNA-mediated and dependent on the dosage of the $\mathrm{CP}$ gene, $\mathrm{CP}$ sequence homology of the challenge virus, and plant development stage. Thus, the hemizygous 'Rainbow' is resistant to Hawaiian isolates, but susceptible to isolates from outside of Hawaii whereas homozygous 'SunUp' is resistant to the tested isolates from outside of Hawaii, with the exception of the Thailand isolate.

Given its adaptability to growing in the Puna area, its yellow-flesh fruit (versus redflesh of 'SunUp'), and its superior shipping quality (Hamilton and Ito, 1968), the transgenic cultivar 'Rainbow' is more popular than 'SunUp'. However, the rather narrow resistance of 'Rainbow' pointed to the need for additional transgenic papaya lines. Consequently, further screening was done with other primary transformants from the transformation experiment that produced line $55-1$. $\mathrm{R}_{0}$ plants of a line designated as 63-1 showed resistance to a severe strain of the virus, PRSV HA, from Hawaii. In this work, the resistance of the $\mathrm{R}_{1}$ plants of line 63-1 was further examined against PRSV isolates from Hawaii and different geographical locations.

\section{Materials and Methods}

Transgenic material. Line 63-1 was generated from the same transformation experiment that resulted in line 55-1. Development of line 55-1 that expresses the CP gene of PRSV HA 5-1 was previously described by Fitch et al. (1992) and Tennant et al. (1994). The nontransgenic parent was the red-flesh 'Sunset' cultivar (Hamilton etal., 1993), a sib line of 'Sunrise solo' (Hamilton and Ito, 1968). In initial experiments, $\mathrm{R}_{0}$ clones of line $63-1$ were challenged with the severe isolate PRSV HA. Plants that remained symptomless after inoculation and 2 years thereafter were maintained in the greenhouse at New York State Agricultural Experiment Station, Geneva. A bisexual plant was allowed to self pollinate and progenies from this plant were used in the study.

Detection of CP transgene and analysis of transcript accumulation. DNA was isolated from leaves $(100 \mathrm{mg})$ of seedlings of line 63-1 growing in the greenhouse (Sambrook et al., 1989). The presence of the CP gene was assayed by polymerase chain reaction (PCR) using oligonucleotides (5' ATCATTCCATGGTCAAGGGGCACTGATGA 3' and 5' AGCTAACCATGGGGTGAAACAGGGTCG 3') specific for a 996-kb fragment of the CP gene (Quemada et al., 1990). PCR reactions were run using the Gene AmpR reagent kit with native Taq DNA polymerase following the instructions of the manufacturer (Perkin Elmer Corp., Norwalk, Conn.) and 50 to $100 \mathrm{ng}$ template DNA and $100 \mathrm{ng}$ of each primer. Cycling parameters included one cycle of 5 min at $92^{\circ} \mathrm{C}, 30$ cycles of $1 \mathrm{~min}$ at $92^{\circ} \mathrm{C}$, $1 \mathrm{~min}$ at $55^{\circ} \mathrm{C}, 2.5 \mathrm{~min}$ at $72{ }^{\circ} \mathrm{C}$ and a final cycle of $7 \mathrm{~min}$ at $72{ }^{\circ} \mathrm{C}$. PCR products were analyzed in a $1 \%$ agarose gel. 
Total RNA was isolated from young leaves (top second or third leaf) of transgenic seedlings as described previously by Napoli et al. (1990). Ten micrograms of RNA were electrophoresed in a denaturing formaldehyde agarose gel $(1.2 \%)$. The gel was stained with ethidium bromide $\left(0.5 \mu \mathrm{g} \cdot \mathrm{mL}^{-1}\right)$ to verify the uniformity of RNA in each lane. Membrane transfer, blotting and hybridisation procedures were performed according to the directions supplied with the nylon membrane (DuPont Co., Boston, Mass.). Blots were probed with ${ }^{32} \mathrm{P}$ labelled $\mathrm{NcoI}$ fragment of the PRSV HA 5-1 CP gene (Quemada et al., 1990; Tennant et al., 2001) and subsequently used to expose Kodak X-OMAT film. Autoradiographs were developed according to the manufacturer's recommendations (Sigma, St. Louis, Mo.).

Analysis of transgene expression. Double antibody sandwich enzyme-linked immunosorbent assays were used to detect $\mathrm{CP}$ (CP ELISA) in plants using the protocol described by Ling et al. (1991) and Tennant et al. (1994). Polyclonal antisera to the mild PRSV HA 5-1 from Hawaii were used to coat ELISA plates $\left(2 \mathrm{mg} \cdot \mathrm{mL}^{-1}\right)$ and monoclonal antisera to PRSV HA 5-1 conjugated to alkaline phosphatase $(1: 1500)$ were used for CP detection. Plant cellular extracts were prepared using leaf discs ( 2 to $7 \mathrm{mg}$ ) homogenized in extraction buffer (1:50 w/v; $0.25 \mathrm{M}$ potassium phosphate, 0.01 M ethylene diaminetetraacetic acid, disodium salt, $\mathrm{pH}$ 7.5). Nontransformed 'Sunrise solo' papaya extracts and extraction buffer were included in the assays as negative controls and nontransformed papaya infected with PRSV HA 5-1 as positive controls. All samples and controls were added in duplicate to the microtiter plates. The reaction was read one hour after the addition of substrate (1 $\mathrm{mg} \cdot \mathrm{mL}^{-1} p$ nitrophenyl phosphate) at $\mathrm{OD}_{405 \mathrm{~mm}}$ with a MicroELISA Autoreader (Dynatech Inc., Chantilly, VA). Reactions with an average absorbance reading of $\geq 0.100$ were regarded as positive. Similarly, neomycin phospho-

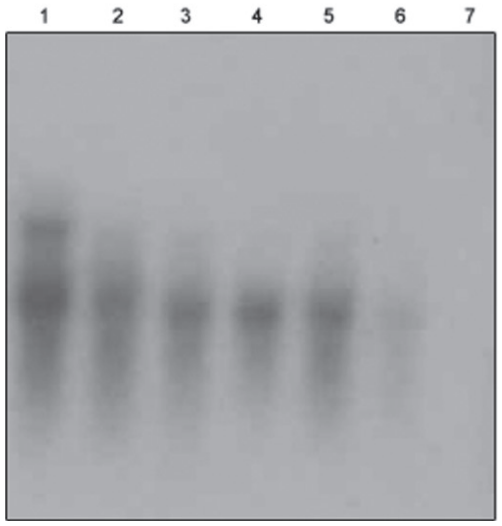

Fig. 1. Northern blot analysis of $\mathrm{CP}$ from transgenic papaya line 63-1 before mechanical challenge. Total RNA $(10 \mu \mathrm{g})$ electrophoresed under denaturing conditions was probed with a ${ }^{32} \mathrm{P}$ labelled DNA specific for the papaya ringspot virus (PRSV) HA 5-1 CP- gene sequence. Lanes 1 to $6=$ samples from six different plants of line 63-1 and Lane 7 = nontransgenic 'Sunrise solo' papaya control. The arrow denotes the position of the $\mathrm{CP}$ transcript. transferase II (NPTII) expression was detected by ELISA assays (NPTII ELISA) using kits from 5 Prime-3 Prime Inc. (Boulder, Colo.). Sample collection and preparation were the same as those used in the CP ELISA assays. Nontransformed 'Sunrise solo' papaya and transgenic 55-1 papaya (that tested positive for NPTII in previous analyses) were used as negative and positive controls, respectively. Coating antisera, biotinylated antisera, and the streptavidin conjugate were used at dilutions of 1:1000, 1:2000, and 1:2500, respectively. Reactions were read at $\mathrm{OD}_{405 \mathrm{~mm}} 20$ min after the addition of substrate $(1 \mathrm{mg} / \mathrm{ml} p$ nitrophenyl phosphate); an average absorbance reading of $\geq 0.100$ was regarded as positive.

Inoculation of plants with PRSV. Transgenic and nontransgenic seedlings were mechanically inoculated with a 1:20 dilution of leaf extracts of Cucumis metuliferus (extraction buffer: $0.01 \mathrm{M}$ potassium phosphate, $\mathrm{pH}$ 7.5 ) individually infected for $21 \mathrm{~d}$ with PRSV isolates from Hawaii (HA severe, Oahu OA, Kapoho KA, and Keauu KE), Brazil (BR), Thailand (TH), and Jamaica (JA) (Tennant et al., 1994). Inoculum was applied to the three youngest fully expanded leaves of plants predusted with carborundum (Universal Photonics, Inc., Hicksville, N.Y.). All inoculated plants were observed daily for about 8 weeks. Disease resistance was assessed by comparing symptom development (vein clearing, mosaic, leaf distortion, leaf reduction) and the severity of symptoms on new growth of transgenic and nontransgenic seedlings. Three to four weeks after inoculation, symptomless plants were reinoculated mechanically or by approach grafting (Garner, 1988) to infected nontransgenic plants of 'Sunrise solo' papaya. In the first stage of the graft inoculation, a transgenic plant and nontransgenic plant were transplanted to a single pot. A slice of stem (about 3 to $4 \mathrm{~cm}$ at a height of 10 to $15 \mathrm{~cm}$ from soil level) was cut from both stems, the cut surfaces joined, and bound tightly by grafting bands and parafilm. Within 5 to 7 weeks after the stems were joined, the second stage was conducted whereby the transgenic shoot was severed below the graft union, the nontransgenic canopy was cut away thus making the transgenic plant totally dependent on the roots of the infected nontransgenic plant. Grafted plants were observed daily over 8 weeks. Following the period of observation, a few grafted plants were severed just above the roots, the cut end placed in a $1 \%$ aqueous acid fuchsin solution and placed under a light source for 2 to $4 \mathrm{~h}$ (M. Goffinet, personal communication). Transverse cuts were taken through, above, and below the graft union and examined for perfusion of the dye.

\section{Results}

Prior to infectivity studies of the progeny, NPTII ELISA and CP ELISA were conducted to identify transgenic plants. $R_{1}$ seedlings of line 63-1 generally had high NPTII ELISA OD readings; an absorbance range of 0.070 to 0.489 was observed with $75 \%$ of 78 seedlings tested. In CPELISA, $94 \%$ of the 83 tested $\mathrm{R}_{1}$ seedlings showed readings of 0.100 to 0.861 , much higher than previously reported with 55-1 plants (Tennant et al., 1994). To more precisely define the presence of the CP transgene, 50 plants were tested by PCR with primers to the $\mathrm{CP}$ gene. The gene was detected in 47 of the 50 plants tested; a good fit to a 15:1 segregation ratio $(p \leq 0.05)$ suggesting the presence of two independently segregating loci in line 63-1. Northern analysis of selected transgenic plants showed variable intensity of CP transcripts, which was not surprising given the variability in the CP level as measured by ELISA (Fig. 1).

Unlike $\mathrm{R}_{1}$ plants of line 55-1 (Tennant et al., 1994), which were uniformly resistant to PRSV isolates from Hawaii, a significant number of transgenic $\mathrm{R}_{1}$ plants of 63-1 showed symptoms following inoculation by Hawaiian isolates (Table 1). The percentage of plants that were resistant ranged from $69 \%$ for $\mathrm{HA}$ and $\mathrm{KA}$ isolates, to $59 \%$ and $40 \%$ for $\mathrm{OA}$ and $\mathrm{KE}$ isolates respectively. Interestingly, infected 63-1 plants did not show the same symptomatology as susceptible derivatives of the line 55-1 or nontransgenic papaya (Fig. 2). Typically, PRSV infection begins with vein clearing followed by mosaic development, severe leaf distortion, and a reduction in leaf size (shoe-stringing). Susceptible transgenics of line 63-1 initially developed chlorotic spots and later severe mosaic symptom expression (usually after a delay of up to $27 \mathrm{~d}$ ). Moreover, symptoms were not uniformly expressed over leaf surfaces or on all leaves.

To assess the durability of resistance to graft inoculation, six transgenic plants that resisted mechanical inoculation with PRSV were selected and divided into two sets of three plants for approach grafting with nontransgenic seedlings infected with PRSV HA or OA(Table 2, Fig. 3). In each set, two of the three test plants remained symptomless, even after the stems of

Table 1. Reaction of $\mathrm{R}_{1}$ plants of transgenic line 63-1 to mechanical inoculations with PRSV isolates from Hawaii and other geographical locations.

\begin{tabular}{lccccc}
\hline & \multicolumn{3}{c}{ Reaction $^{2}$ of plants to inoculation with PRSV } \\
\cline { 2 - 3 } \cline { 5 - 6 } PRSV isolates & \multicolumn{2}{c}{$\mathrm{R}_{1}$ transgenic 63-1 } & plants & & Nontransgenic plants \\
\cline { 2 - 3 } \cline { 5 - 6 } No. plants & Resistant (\%) & & No. plants & Resistant (\%) \\
\hline Hawaii & 52 & 69 & & 9 & 0 \\
HA & 22 & 59 & & 15 & 0 \\
OA & 16 & 69 & & 15 & 0 \\
KA & 25 & 40 & & 7 & 0 \\
KE & 39 & 87 & & 17 & 0 \\
Other & 26 & 38 & & 12 & 0 \\
Jamaica & 35 & 29 & & 10 & 0 \\
Brazil & & & & \\
Thailand & 35 &
\end{tabular}

${ }^{2}$ Resistant plants were inoculated twice and did not show symptoms throughout the 60-d observation period. 
the transgenic plants were severed to make the transgenic canopies dependent on the infected nontransgenic papayas for survival. The transgenic plants that became infected showed a delay in symptom development of $28 \mathrm{~d}$ after stage I or stage II (Table 2). Transverse cuts through the graft union revealed good callusing of tissue and xylem connection (Fig. 4).
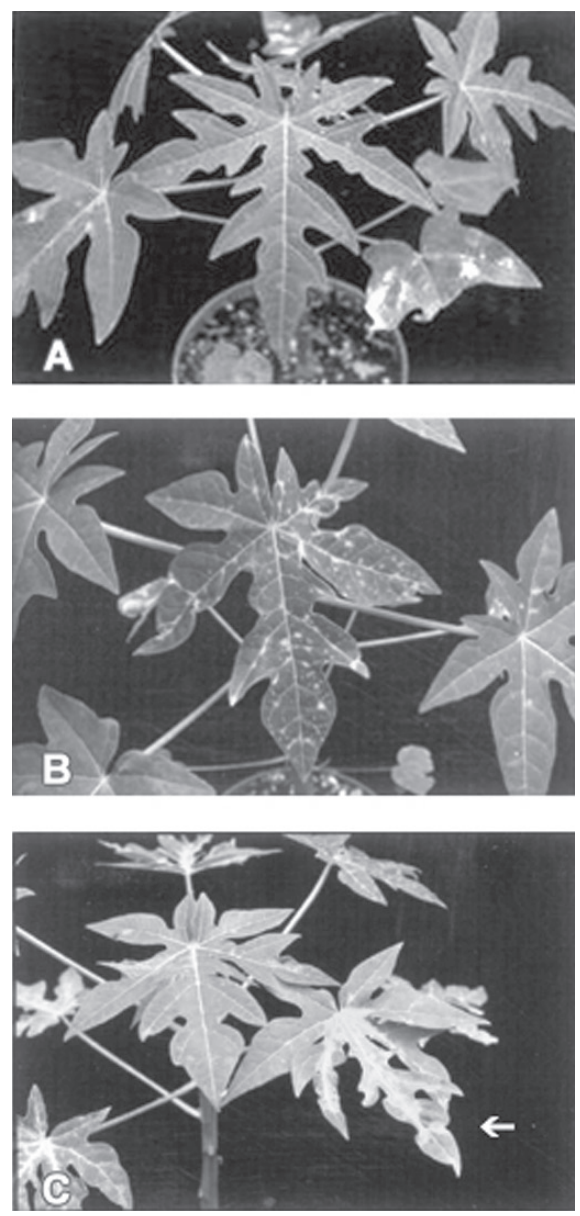

Fig. 2. Differential resistance phenotypes of transgenic plants following mechanical inoculation with extracts from Cucumis metuliferus infected with severe papaya ringspot virus (PRSV) HA isolate. (A) Asymptomatic plant at $42 \mathrm{~d}$ postinoculation with PRSV HA. (B) Chlorotic mottle. (C) Asymptomatic fully expanded first leaf and localised severe mosaic and leaf distortion symptoms on third leaf (as indicated by arrow).
An important question of this study was to determine the response of line 63-1 to inoculation with non-Hawaiian PRSV isolates from other geographical regions. In our previous work on line 55-1, it was shown that $\mathrm{R}_{1}$ plants were largely susceptible to PRSV originating outside of Hawaii (Tennant et al., 1994, 2001). To allow a comparison with line 55-1 results to 63-1, isolates from Brazil (BR), Thailand $(\mathrm{TH})$, and Jamaica (JA) were tested on $\mathrm{R}_{1}$ plants of line 63-1. These isolates infected $R_{1}$ plants of line 55-1 with TH and BR inducing severe symptoms and JA inducing attentuated symptoms (Tennant et al., 1994).

The reactions of $\mathrm{R}_{1}$ plants of line 63-1 that were challenged with PRSV isolates from regions outside of Hawaii were striking when compared to previous inoculations involving $\mathrm{R}_{1}$ plants of line 55-1 (Tennant et al., 1994). Unlike the reactions of line 55-1, a significant number of line 63-1 $R_{1}$ plants were resistant to PRSV BR, JA, and TH (Table 1). Of the transgenic plants inoculated with isolates from Thailand, Brazil, and Jamaica, 29\%, 38\%, and $87 \%$, respectively, remained symptomless after two mechanical inoculations (Table 1). The symptoms and their pattern of development on susceptible plants were similar to those observed for plants inoculated with Hawaiian isolates.

Plants that remained healthy after two mechanical inoculations with PRSV BR were subsequently graft inoculated to nontransgenic papaya infected with the BR isolate. Only one of the six grafted transgenic plants developed attenuated symptoms after a long delay of 56 d (Table 2).

\section{Discussion}

The commercial transgenic cultivar 'Rainbow' derived from line 55-1 and presently available to papaya growers in Hawaii shows excellent resistance to PRSV isolates from Hawaii, but almost no resistance to isolates from outside of Hawaii. We have identified and evaluated the resistance of another transgenic line (63-1) that also shows resistance to PRSV isolates from Hawaii. In addition, a portion of 63-1 $\mathrm{R}_{1}$ transgenic plants are resistant to non-Hawaiian PRSV isolates that can infect 'Rainbow'. Line 63-1 represents another potential transgenic

Table 2. Response of $\mathrm{R}_{1}$ plants of transgenic line 63-1 to approach graft inoculations with PRSV isolates.

\begin{tabular}{|c|c|c|c|c|}
\hline \multirow[b]{2}{*}{ PRSV } & \multirow[b]{2}{*}{ No. of plants } & \multicolumn{2}{|c|}{ Reaction $^{z}$ at graft stage } & \multirow{2}{*}{$\begin{array}{l}\text { Days for symptom } \\
\text { expression }\end{array}$} \\
\hline & & I & II & \\
\hline \multicolumn{5}{|c|}{ Hawaiian isolates } \\
\hline HA & 1 & NS & $\mathrm{S}$ & 28 \\
\hline HA & 2 & NS & NS & NA \\
\hline $\mathrm{OA}$ & 1 & $\mathrm{~S}$ & NA & 28 \\
\hline $\mathrm{OA}$ & 2 & NS & NS & NA \\
\hline \multicolumn{5}{|c|}{ Other isolates } \\
\hline $\mathrm{BR}$ & 1 & NS & MM & 56 \\
\hline $\mathrm{BR}$ & 5 & NS & NS & NA \\
\hline
\end{tabular}

${ }^{2}$ Nontransgenic papaya plants, previously mechanically inoculated (14 to $21 \mathrm{~d}$ ), were approach grafted to transgenic $\mathrm{R}_{1}$ plants. At stage I, both rooted plants were joined by an approach graft and in stage II, the transgenic stem was severed below the graft union, the symptomatic canopies of the nontransgenic plants were cut away, thus making survival of the transgenic scion dependent on the virus infected nontransgenic root. Leaf canopies of transgenic plants were rated as NS = no symptoms, $\mathrm{S}=$ severe symptoms, $\mathrm{MM}=$ mild mosaic; NA = symptom reading not applicable. papaya line that could be used to combat PRSV in Hawaii and elsewhere.

Line 63-1 is an interesting model to contrast with line $55-1$ because it has the same CP transgene as line 55-1, yet exhibits differences in resistance to a range of PRSV isolates. Recently, we showed that resistance of line $55-1$ is mediated via post-transcriptional gene silencing and that resistance to different PRSV isolates is affected by gene dosage and plant age (Tennant et al., 2001). Hemizygous plants ('Rainbow') show resistance to only PRSV isolates with high sequence homology to the CP transgene (mild strain PRSV HA 5-1) whereas homozygous plants ('SunUp') show resistance to more distantly related isolates (e.g., BR, JA). It is reasonable to assume that the mechanism of resistance of 63-1 is similar to that of 55-1 (i.e., post-transcriptional gene silencing). Since line 55-1 has one CP insert and line 63-1 has at least two segregating gene inserts (this work), the differences in the reactions of the $\mathrm{R}_{1}$ plants of line 55-1 and 63-1 may be largely due to a gene dosage effect. The $\mathrm{R}_{1}$ progeny of line 55-1 segregated in the ratio of 1 transgenic: 1 nontransgenic plant, because the original $\mathrm{R}_{0}$ transformant was pistillate and had to be backcrossed with a bisexual plant of a nontransgenic parental 'Sunset' line. Consequently, all 55-1 $\mathrm{R}_{1}$ transgenics were uniformly hemizygous at the single CP transgene locus (similar to Rainbow). However, $\mathrm{R}_{1}$ progeny of 63-1 were produced by self-pollination of the original $\mathrm{R}_{0}$ transformant and this should result in a more complex segregation, typical of an $\mathrm{F}_{2}$ population. Assuming that two $\mathrm{CP}$ transgenes are segregating independently in the 63-1 $\mathrm{R}_{1}$ generation, eight different (co-dominant) genotypes with potentially different transgene dosages could result. $R_{2}$ and $R_{3}$ populations of line 63-1 are being studied in more detail to determine the role of transgene dosage in resistance to the range of isolates used in this work (Souza 1999).

Our results of greater resistance against non-Hawaiian isolates than Hawaiian isolates are similar to the results of two recent studies with transgenic papaya developed for Venezuela and Taiwan. Fermin et al. (2004) reported that all $R_{0}$ transgenic lines transformed with a severe $\mathrm{CP}$ gene from Vigia (EV) Venezuela, were completely susceptible to mechanical challenge with PRSV EV. $\mathrm{R}_{1}$ progenies showed 0 to $7 \%$ resistance against PRSV EV but $50 \%$ to $73 \%$ against LA (another Venezuelan isolate) and $50 \%$ to $60 \%$ against the Hawaiian HA isolate. Sequence similarities between the CP transgene and these challenge isolates were $100 \%, 92 \%$, and $94 \%$, respectively. In Taiwan, transgenic papaya lines carrying the CP gene of the YK strain of PRSV exhibited resistance against isolates from Hawaii (HA), Mexico (MX) and Thailand (TH) but resistance was not conferred against local strains (Tripathi et al., 2004). Molecular characterization of the local isolates revealed high sequence similarities ranging from $95 \%$ to $96.5 \%$ to the $\mathrm{YK}$ strains while sequence similarities between YK and HA, MX and TH were $91.2 \%, 89.8 \%$, and $92.6 \%$, respectively. It was concluded in both studies that the level of resistance conferred by $\mathrm{CP}$ genes in transgenic 

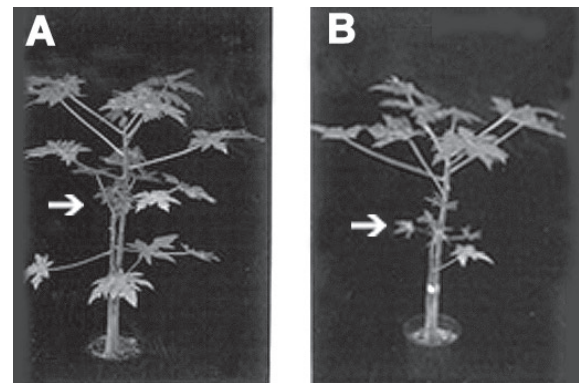

Fig. 3. Typical set up of approach graft inoculated plants (at stage I before severing the stem of the transgenic plant below the graft union). Note asymptomatic transgenic 63-1 plants grafted to nontransgenic plant infected with papaya ringspot virus (PRSV) HA (A) and PRSV OA (B). Arrow indicates symptomatic nontransgenic papaya (reduced and deformed canopies).
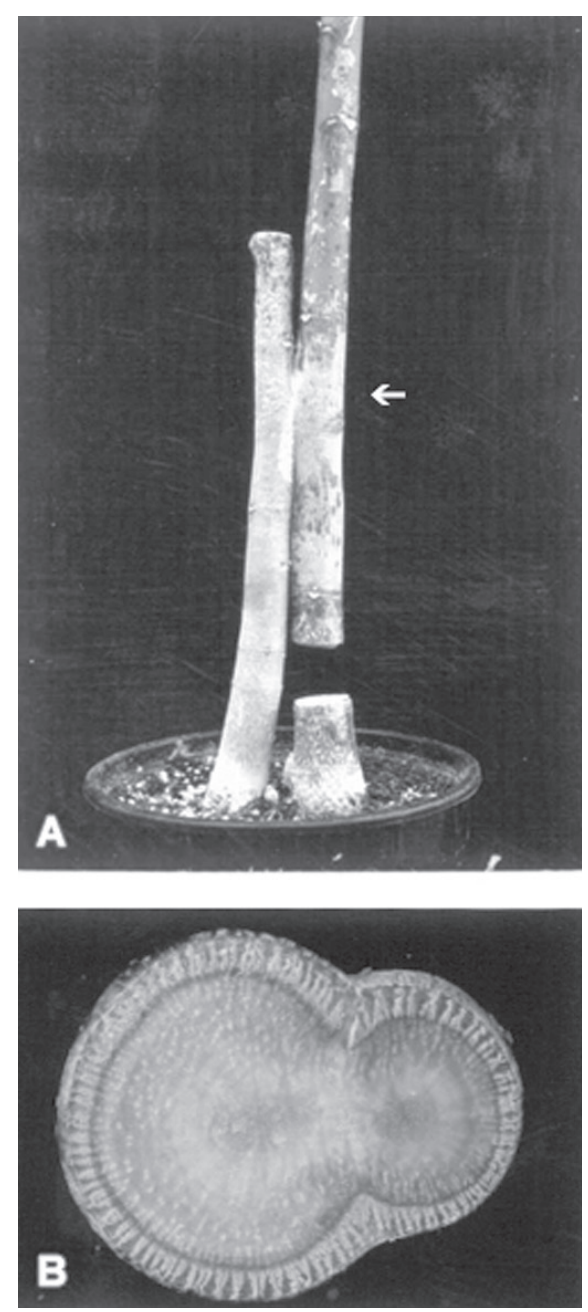

Fig. 4. Graft inoculated transgenic plant totally dependent on the papaya ringspot virus (PRSV) infected nontransgenic (stage II). (A) Integrity of the graft union was determined by examination of sections through the union (where indicated by the arrow) after dye was drawn up through stems severed above the roots. Good knitting of the tissue and transport of the dye through the union are shown in (B). plants is not solely dependent on a high degree of similarity between the CP transgene and the challenge virus. Tripathi et al. (2004) and others (Anadalakshmi et al., Brigneti et al., and Kasschau and Carrington, 1998) make reference to the suppression of the transgenic resistance mechanism by other viral genes [such as the virus helper component proteinase (HC-Pro)]

Arguably, the greatest potential danger to the Hawaiian industry is the introduction and establishment of non-Hawaiian PRSV isolates in Hawaii. The most important isolates would be, for example, from Thailand and Taiwan because they overcame the resistance of 'SunUp'. However, 'SunUp' has some resistance to these virulent strains, in that it displays milder symptoms when infected than 'Rainbow' or nontransgenic plants, it becomes more resistant with age, and some inoculated plants fail to become infected at all (Chiang et al., 2001; Tennant et al., 2001). In this work, a percentage of plants of the $R_{1}$ generation of 63-1 showed resistance to PRSV Thailand. Since a yellow-flesh papaya with added properties of the nontransgenic 'Kapoho' (i.e., 'Rainbow') is preferred by Hawaiian farmers and consumers alike, a similar hybrid could be attempted from a cross between a plant that combines $\mathrm{CP}$ genes from both line 55-1 and from line 63-1 in a homozygous state and the nontransgenic 'Kapoho' cultivar might provide the necessary resistance to Thailand and Taiwanese isolates and yet have identical or very similar horticultural properties to 'Rainbow'. Recent work with transgenic squash, for example, has shown that hybrids with genes from two lines show high resistance to squash mosaic virus, even though the parents show low levels of resistance (Jan et al., 2000).

A major objective of this work was to evaluate other potential transgenic papaya lines that could be useful to ensure availability of transgenic papaya with durable resistance and desirable horticultural properties. Line 63-1 fits this category for several reasons: it was derived from 'Sunset', a cultivar of known horticultural quality (also highly desired in other papaya growing regions, such as Brazil), it appears to be resistant to a broader geographic range of PRSV isolates than line 55-1, it might be bred with line 55-1 to obtain a cultivar that has higher resistance than either line alone, and importantly, it has already been deregulated by USDA-APHIS (1996) and EPA(1997). Lastly, recent information on field trials in Hawaii with $R_{2}$ progenies of line 63-1 report on good PRSV resistance and agronomic performance (Ferreira et al., 2002).

\section{Literature Cited}

Anandalakshmi, R., G. Pruss, X. Ge, R. Marathe, A. Mallory, T. Smith, and V. Vance. 1998. A virus suppressor gene silencing in plants. Proc Nat Acad Sci USA 82:3969-3972.

Brigneti, G., O. Voinnet, W. Li, S. Ding, and D. Baulcombe. 1998. Viral pathogenicity determinants are suppressors of transgene silencing in Nicotiana benthamiana. EMBO J. 17:6739-6746.

Chiang, C.-H., F.-J. Jan, S.-D. Yeh, and D. Gonsalves. 2001. Comparative reactions of recombinant papaya ringspot viruses with chimeric coat protein $(\mathrm{CP})$ genes and wild-type viruses on CP-transgenic papaya. J. Gen. Virol. 82:2827-2836

Kasschau, K. and J. Carrington. 1998. A counter defensive strategy of plant viruses: Suppression of post-transcriptional gene silencing. Cell 95:461-470.

Fermin, G., V. Inglessis, C. Garboza, S. Rangel, M. Dagert, and D. Gonsalves. 2004. Engineered resistance against papaya ringspot virus in Venezuelan transgenic papayas. Plant Dis. 88:516-522.

Ferreira, S., K. Pitz, R. Manshardt, F. Zee, M. Fitch, and D. Gonsalves. 2002. Virus coat protein transgenic papaya provides practical control of papaya ringspot virus in Hawaii. Plant Dis. 86:101-105.

Fitch, M.M.M., R.M. Manshardt, D. Gonsalves, J.L. Slightom, and J.C. Sanford. 1992. Virus resistant papaya plants derived from tissues bombarded with the coat protein gene of papaya ringspot virus. Bio/Technology 10:1466-1472.

Garner, R.J. 1988. The grafters' handbook. Oxford Univ. Press, New York.

Gonsalves D. 1998. Control of papaya ringspot virus in papaya: A case study. Annu. Rev. Phytopathol. 36:415-437.

Hamilton, R.A. and P. Ito. 1968 'Sunrise solo'-Adifferent colored Solo papaya. Hawaii Agr. Expt. Sta. Circ. 69.

Hamilton, R.A., P.J. Ito, and R.E. Paull. 1993. 'Sunset solo' papaya. Hawaii Coop. Ext. Serv. Commodity Fact Sheet PA-(B) June.

Jan, F., S. Pang, D. Tricoli, and D. Gonsalves. 2000. Evidence that resistance in squash mosaic comovirus coat proteintransgenic plants is affected by plant developmental stage and enhanced by combination of transgenes from different lines. J. Gen. Virol. 81:2299-2306.

Ling, K., S. Namba, C. Gonsalves, J.L. Slightom, and D. Gonsalves. 1991. Protection against detrimental effects of potyvirus infection in transgenic tobacco plants expressing the papaya ringspot virus coat protein gene. Bio/Technology 9:752-758.

Manshardt R. 1998. 'UH Rainbow' papaya. Univ. Hawaii Coll. Trop. Agr. Human Resour. Germplasm G-1.

Napoli, C., C. Lemieux, and R. Jorgensen. 1990. Introduction of a chimeric chalcone synthase gene into petunia results in reversible co-suppression of homologous genes in trans. Plant Cell 2:279-289.

Purcifull, D., J. Edwardson, E. Hiebert, and D. Gonsalves. 1984. Papaya ringspot virus. CMI/AAB descriptions of plant viruses. No. 292. (No. 84 Revised, July 1984).

Quemada, H., B. L'Hostis, D. Gonsalves, I. Reardon, R. Heinrikon, E. Hiebert, L. Sieu, and J. Slightom. 1990. The nucleotide sequences of the 3' terminal regions of papaya ringspot virus strains W and P. J. Gen. Virol. 71:203-210.

Sambrook, J., E.F. Fritsch, and T. Maniatis. 1989. Molecular Cloning: A laboratory manual. 2nd ed. Cold Spring Harbor Laboratory, Cold Spring Harbor, N.Y.

Souza Júnior, M.T. 1999. Analysis of the resistance in genetically engineered papaya against papaya ringspot potyvirus, partial characterization of the PRSV.Brazil. Bahia isolate, and development of transgenic papaya for Brazil. PhD diss. Cornell Univ., Ithaca, N.Y.

Tennant P.F., C. Gonsalves, K.S. Ling, M. Fitch, R. Manshardt, J.L. Slightom, and D. Gonsalves. 1994. Differential protection against papaya ringspot virus isolates in coat protein gene transgenic papaya and classically cross-protected papaya. Phytopathology 84:1359-1366.

Tennant, P., Fermin, G., Fitch, M., Manshardt, R., Slightom, J., and Gonsalves, D. 2001. Papaya ringspot virus resistance of transgenic Rainbow and SunUp is affected by gene dosage, plant development, and coat protein homology. Eur. J. Plant Pathol. 107:645-653.

Tripathi, S., H. Bau, L.-F. Chen, and S.-D. Yeh. 2004. The ability of papaya ringspot virus strains overcoming the transgenic resistance of papaya conferred by the coat protein gene is not correlated with higher degrees of sequence divergence from the transgene. Eur. J. Plant Path. 110: 871-882

U.S. Dept. of Agriculture-APHIS. 1996. Cornell University and the University of Hawaii; Availability of determination of nonregulated status for papaya lines genetically engineered for virus resistance. Fed. Reg. 61:48663-48664

U.S. Environmental ProtectionAgency. 1997. Coat protein of papaya ringspot virus and the genetic material necessary for its production; Exemption from the requirement of tolerance. Fed. Reg. 62:44572-44575. 